\title{
IDENTIFICATION OF ANTIHYPERTENSIVE PEPTIDES IN NUTRACEUTICALS BY CAPILLARY ELECTROPHORESIS-MASS SPECTROMETRY
}

Fernando Benavente ${ }^{\mathrm{a}, *}$, Roger Pero-Gascon ${ }^{\mathrm{a}}$, Laura Pont ${ }^{\mathrm{a}}$, Joaquim Jaumot ${ }^{\mathrm{b}}$, José Barbosa $^{\mathrm{a}}$, Victoria Sanz-Nebot ${ }^{\mathrm{a}}$

${ }^{a}$ Department of Chemical Engineering and Analytical Chemistry, Institute for Research on Nutrition and Food Safety (INSA.UB), University of Barcelona, Martí i Franquès 1$11,3^{\text {rd }}$ floor, 08028, Barcelona, Spain.

bDepartment of Environmental Chemistry, IDAEA-CSIC, Jordi Girona 18-26, 08034, Barcelona, Spain.

*Corresponding author: fbenavente@ub.edu (F. Benavente, PhD) Tel: (+34) 934039116 Fax: (+34) 934021233

Declarations of interest: none

KEYWORDS: Bioactive peptides; Capillary electrophoresis; Chemometrics; Foodomics; Peptidomics; Mass spectrometry

\section{Non-standard abbreviations:}

BGE: background electrolyte

CE-MS: capillary electrophoresis-mass spectrometry

CSN: casein

EIE: experimental extracted ion electropherogram 
HAc: acetic acid

HFor: formic acid

MCR-ALS: multivariate curve resolution alternating least squares

ROIs: regions of interest

TIE: total ion electropherogram 


\begin{abstract}
We present capillary electrophoresis-mass spectrometry (CE-MS) in combination with advanced chemometric tools for the analysis of bioactive compounds in food, in particular for the identification of antihypertensive peptides in a nutraceutical derived from a bovine milk protein hydrolysate. Different extracts of the nutraceutical were analyzed by CE-MS, and the electropherograms were processed using a novel data analysis workflow that included regions of interest (ROIs) compression and multivariate curve resolution alternating least squares (MCR-ALS). MCR-ALS permitted the description of the nutraceutical extract as ten characteristic components with their electrophoretic profiles and mass spectra. Twenty-two compounds were tentatively identified as antihypertensive bovine casein fragments through a mass search in a database of bioactive peptides. The identity of 17 antihypertensive peptides was reliably confirmed by capillary electrophoresis-tandem mass spectrometry. The proposed analytical approach demonstrated the potential to obtain a characteristic and activityrelated fingerprint for quality control and authentication of the antihypertensive nutraceutical.
\end{abstract}




\section{Introduction}

Many peptide fragments derived from food protein hydrolysates are of great interest in food and pharmaceutical sciences because they present different physiological roles, providing benefits in human health [1-6]. Milk and milk-derived protein hydrolysates are one of the most studied sources of biologically active peptides and they are regarded as potential ingredients of functional dairy foods, nutraceuticals, and cosmetics [1-3]. Bovine milk is accessible and inexpensive and contains approximately $3.5 \%(\mathrm{~m} / \mathrm{m})$ of proteins, with $80 \%(\mathrm{~m} / \mathrm{m})$ of casein $(\mathrm{CSN})$ and $20 \%(\mathrm{~m} / \mathrm{m})$ of whey proteins [1]. Many bovine CSN and whey protein fragments with different bioactivities have been described, including, among others, immunostimulation, antimicrobial, opioid, metal binding, antithrombotic, allergenic and angiotensin converting enzyme (ACE) inhibition [1-3,7-9]. ACE inhibitors are by far the largest and most investigated group, as it is evidenced by the number of papers published on this topic that are cited in the most comprehensive on-line databases, such as BIOPEP [7] (a general database of bioactive peptides, http://www.uwm.edu.pl/biochemia/index.php/pl/biopep), AHTPDB [8] (a specific database of antihypertensive peptides, http://crdd.osdd.net/raghava/ahtpdb/) or MBPDB [9] (a specific database of bioactive peptides in milk, http://mbpdb.nws.oregonstate.edu/). ACE participates in blood pressure regulation and inhibition of this enzyme, which has been demonstrated in most cases in vitro, could have an antihypertensive effect in vivo [2,8]. With this idea in mind, over the past years, several antihypertensive functional foods and nutraceuticals have been launched worldwide [2,10]. Consumer awareness about the benefits of these state-of-the-art pharmaco-nutritional products with bioactive peptides is continuously increasing, but also the concerns about the absence of reliable clinical trials supporting evidence for 
health claims in vivo, allergenicity, cytotoxicity and stability of the peptides during gastrointestinal digestion [2]. Furthermore, it is necessary to develop novel analytical methods for the characterization of functional foods and nutraceuticals with bioactive peptides, as part of quality control, food safety and fraud control programs [11,12].

Most of the methods that have been developed for the analysis of peptides in milk protein hydrolysates in a wide variety of food products are based on reversed-phase liquid chromatography-mass spectrometry (LC-MS) [10-12]. Capillary electrophoresismass spectrometry (CE-MS) has been applied to a lower extent [11-15], despite the many and well-known benefits of this high-performance separation technique based on electromigration, which provides complementary, and very often better, separations than hydrophobicity-driven reversed-phase LC-MS, especially for charged polar compounds [16]. In this respect, we have described a CE-MS method to identify the presence of bioactive peptides in several commercial hypoallergenic infant formulas manufactured by hydrolysis of bovine milk proteins to diminish the risk of protein allergy [13,14]. A sample clean-up and preconcentration using a citrate buffer with dithiothreitol (DTT) and urea followed by solid-phase extraction (SPE) with a C18 sorbent was applied before CE-MS. Then, features and bioactive peptides were searched in the electropherograms using the typical tools of the commercial software packages provided with the mass spectrometer $[13,14]$ or similar alternatives freely available online [15], which very often are difficult and tedious to use and must be carefully applied to avoid biased and unreliable results. As an alternative to this traditional data analysis methods, here, using as a case study a topic of interest nowadays in food analysis, such as the identification of antihypertensive peptides in a nutraceutical derived from a milk protein hydrolysate, we propose a data analysis workflow for data pre-processing, data 
resolution and untargeted compound (feature) finding based on advanced chemometric tools [17], specifically regions of interest (ROIs) compression [18] and multivariate curve resolution alternating least squares (MCR-ALS) [19,20]. The core of the current data analysis workflow was adapted to be applied for the first time in foodomics from our previous LC-MS and CE-MS studies in metabolomics [21-23], because bioactive peptides are, as metabolites, low molecular mass compounds. For the identification of the selected features, we propose the use of the information available in the most comprehensive and currently updated on-line databases that were indicated above [7-9], which in case of AHTPDB [8] and MBPDB [9] were recently developed. The proposed analytical approach demonstrated a great potential for the simple, rapid and systematic identification of antihypertensive peptides in the nutraceutical sample. The obtained characteristic and activity-related fingerprint of antihypertensive bovine casein peptide fragments for the nutraceutical analyzed in this study could be very useful for quality control and authentication. 


\section{Materials and methods}

\subsection{Chemicals, reagents and samples}

All the chemicals used in the preparation of background electrolytes (BGEs) and solutions were of analytical reagent grade or better. Acetic acid (HAc, glacial), formic acid (HFor, 25\% (v/v)), sodium hydroxide $(\geq 99.0 \%(\mathrm{~m} / \mathrm{m}))$ and water (LC-MS grade) were purchased from Merck (Darmstadt, Germany). Propan-2-ol (LC-MS grade) was purchased from Scharlau (Barcelona, Spain).

The antihypertensive nutraceutical $(\mathrm{N})$ was purchased at a local parapharmacy. In accordance with the information provided by the manufacturer, it is a mixture of vegetal extracts with approximately $9 \mathrm{~g}$ of hydrolyzed casein proteins per $100 \mathrm{~g}$ of nutraceutical (i.e. $62.5 \mathrm{mg} / 1$ tablet). The tablets were stored at room temperature when not in use.

\subsection{Electrolyte solutions, sheath liquid and sample solutions}

The BGE contained $1 \mathrm{M}$ HAc (measured $\mathrm{pH}$ was 2.3) and was passed through a 0.22 $\mu \mathrm{m}$ nylon filter (MSI, Westboro, MA, USA) before analysis. The sheath liquid solution consisted of a mixture of 60:40 v/v propan-2-ol:water with a $0.05 \%(\mathrm{v} / \mathrm{v})$ of HFor. The sheath liquid was degassed for $10 \mathrm{~min}$ by sonication before use $[13,14]$.

Ten nutraceutical tablets were ground together with mortar and pestle until a fine powder was obtained. The powder $(0.15 \mathrm{~g})$ was added to a plastic vial with $1 \mathrm{~mL}$ of warm water (at $45^{\circ} \mathrm{C}$ ) and the mixture was shaken $1 \mathrm{~h}$ at $45^{\circ} \mathrm{C}$ and $700 \mathrm{rpm}[13,14,24]$. Then, the mixture was centrifuged at $7000 \mathrm{x} \mathrm{g}$ for $10 \mathrm{~min}$ at $25^{\circ} \mathrm{C}$. The solid was 
discarded and the supernatant was filtered through a $0.22 \mu \mathrm{m}$ nylon filter before the analysis by CE-MS. Ten independent samples were weighed and prepared from the powdered tablets.

\subsection{Apparatus and procedures}

pH measurements were made with a Crison 2002 potentiometer and a Crison electrode 52-03 (Crison Instruments, Barcelona, Spain). Centrifugal filtration was carried out in a cooled Rotanta 460 centrifuge (Hettich Zentrifugen, Tuttlingen, Germany). Agitation during sample extraction was performed with a Thermo-Shaker TS-100 (Biosan, Warren, USA).

\subsubsection{Capillary electrophoresis-mass spectrometry (CE-MS)}

CE-MS experiments were performed in a 7100 CE system coupled with an orthogonal G1603A sheath-flow interface to a 6220 oa-TOF LC/MS spectrometer (Agilent Technologies, Waldbronn, Germany). The sheath liquid was delivered at a flow rate of 3.3 $\mu \mathrm{L} \cdot \mathrm{min}^{-1}$ by a KD Scientific 100 series infusion pump (Holliston, MA, USA). CEMS control and data acquisition were performed using ChemStation and MassHunter softwares (Agilent Technologies) [13,14].

A $72 \mathrm{~cm}$ total length $\left(\mathrm{L}_{\mathrm{T}}\right)$ x $75 \mu \mathrm{m}$ id $\times 360 \mu \mathrm{m}$ od bare fused-silica capillary supplied by Polymicro Technologies (Phoenix, AZ, USA) was used for the separations. All capillary rinses were performed at high pressure (930 mbar). New capillaries were flushed with 1 $\mathrm{M} \mathrm{NaOH}$ (15 min), water (15 min) and BGE (30 min). The system was finally 
equilibrated by applying the separation voltage $(10 \mathrm{kV})$ for $15 \mathrm{~min}$. Between workdays, the capillary was conditioned by rising successively with $0.1 \mathrm{M} \mathrm{NaOH}(5 \mathrm{~min})$, water (10 min) and BGE (15 min). Both activation and conditioning procedures were performed off-line in order to avoid the unnecessary entrance of $\mathrm{NaOH}$ into the MS system. Samples were hydrodynamically injected at 34 mbar for 15 s. A separation voltage of $10 \mathrm{kV}$ (normal polarity, anode at the injection capillary end) was applied for the electrophoretic separations at $25^{\circ} \mathrm{C}$. Between runs, the capillary was rinsed for $2 \mathrm{~min}$ with water and 2 min with BGE. The working BGE was refreshed after every analysis to ensure optimum separation repeatability.

The accurate mass and high resolution TOF mass spectrometer was tuned and calibrated following the manufacturer's instructions. The TOF mass spectrometer parameters in positive mode were optimized for the analysis of low molecular mass peptides: capillary voltage $4000 \mathrm{~V}$, drying gas $\left(\mathrm{N}_{2}\right)$ temperature $200^{\circ} \mathrm{C}$, drying gas flow rate $4 \mathrm{~L} \cdot \mathrm{min}^{-1}$, nebulizer gas $\left(\mathrm{N}_{2}\right) 7 \mathrm{psig}$, fragmentor voltage $215 \mathrm{~V}$, skimmer voltage $60 \mathrm{~V}$, OCT $1 \mathrm{RF}$ Vpp voltage $300 \mathrm{~V}$. Data were collected in profile at 1 spectrum/s between 200 and $1500 \mathrm{~m} / \mathrm{z}$ with the mass range set to high resolution mode $(4 \mathrm{GHz})$. In order to ensure the accuracy of the molecular mass measurements, a standard solution of neuropeptides was analyzed, as quality control, after analyzing the nutraceutical samples [25].

\subsubsection{Capillary electrophoresis-tandem mass spectrometry (CE-MS/MS)}

CE-MS/MS experiments were performed with the same CE instrument and sheath-flow interface coupled to an MSD ion trap (IT) mass spectrometer (Agilent Technologies). CE/MSD Trap Software (Agilent Technologies) was used for instrument control, data acquisition and data processing. The separation, sheath liquid, capillary voltage, drying 
and nebulizer gas conditions were as in CE-MS. The rest of parameters of the IT mass spectrometers were optimized for the analysis of low molecular mass peptides: voltages on the capillary exit and skimmer were 150 and $50 \mathrm{~V}$, respectively; octopole voltages were 15.41 and $3.34 \mathrm{~V}$ and the octopole radiofrequency was $267.2 \mathrm{Vpp}$; lens voltages were -11.32 and $-100 \mathrm{~V}$ and the trap drive value was 70.4 (arbitrary units). MS/MS analyses were performed on the selected precursor ions (Table S-1) in the scanning range from 80 to $1250 \mathrm{~m} / \mathrm{z}$ with an intensity threshold of 8000 and an MS/MS fragmentation amplitude of $1.0 \mathrm{~V}$ or $2 \mathrm{~V}$ (auto MS/MS mode).

\subsection{Data analysis}

This section and Figure 1 describe the dataset and data analysis workflow followed for data pre-processing, data resolution, feature finding, identification and confirmation of antihypertensive peptides in the nutraceutical sample, which is based on our previous studies in metabolomics [21-23].

\subsubsection{Data pre-processing}

First, CE-MS raw data from the nutraceutical samples were converted to mzXML format with the ProteoWizard software 3.0 (Palo Alto, CA, USA, freely available at http://proteowizard.sourceforge.net) and, then, imported into the MATLAB environment (MATLAB R2013a, The Mathworks Inc. Natick, MA, USA). The input full resolution data matrix was compressed through a "regions of interest" (ROI) search (Fig. 1A) using a home-made MATLAB program (A download link can be found in reference [18] o it is available upon request) [17,18,23]. Using this compression, ROI 
values are searched among every migration time of the considered electrophoretic runs. These vectors with the common ROIs among the different migration times are grouped into a matrix and the final $\mathrm{m} / \mathrm{z}$ values of each ROI are calculated as the mean of the $\mathrm{m} / \mathrm{z}$ values obtained for that specific ROI. The number of rows and columns in the resulting matrix are equal to the total number of migration times of the considered run and to the total number of detected ROIs, respectively.

ROI approach requires the input of several parameters, including the signal-to-noise threshold, the mass accuracy (i.e. $m / z$ error) and the minimum number of migration times to be considered as a peak for each ROI. In our case, after visual inspection of the raw data and different preliminary tests, these parameters were set at 10,000 of MS intensity threshold signal, $0.05 \mathrm{~m} / \mathrm{z}$ of mass accuracy and a minimum number of 25 times in a peak to avoid losing information about low abundant compounds. After ROI compression a considerable size reduction was achieved and only the regions of the raw data with significant information about sample composition were considered for further analysis.

In this case, run-to-run and sample-to-sample intensity reproducibilities were high because different extracts of the same nutraceutical were analyzed. Therefore, it was not necessary to normalize the intensity scale of the MS-ROI data matrices using internal standards. Intensity scale normalization is necessary after MS-ROI compression to correct among run instrumental intensity drifts, differences on sample matrix or any other fonts of low detection reproducibility [17,18,23]. Individual MS-ROI matrices were arranged in a column-wise augmented data matrix to find, by a pairwise search, common and uncommon ROI values among them. This search transformed the original 
individual MS-ROI in data matrices with an equal number of $\mathrm{m} / z$ values (column of the final data matrix). The dimension of the ROI augmented data matrix (Daug, Fig. 1A) was the total number of migration times considered in the whole set of samples (rows) and the total number of considered $\mathrm{m} / \mathrm{z}$ ROI values (columns). The augmented data matrix was considered for MCR-ALS analysis (Fig. 1B).

\subsubsection{MCR-ALS analysis}

MCR-ALS (MCR-ALS 2.0 MATLAB toolbox, freely available at http://www.mcrals.info [20]) was applied to resolve the component profiles from the nutraceutical samples. MCR-ALS resolves as different components the overlapped electrophoretic peaks from the data and provides their electrophoretic profiles and mass spectra. This approach allows overcoming problems such as retention time shifts, background noise contributions, and differences in $\mathrm{S} / \mathrm{N}$ among the different samples.

MCR-ALS analysis of a data matrix $\mathbf{D}$, following a bilinear model, gives the two factor matrices, $\mathbf{C}$ and $\mathbf{S}^{\mathbf{T}}$, as in Eq. 1:

$$
\mathbf{D}=\mathbf{C S}+\mathbf{E}
$$

where matrix $\mathbf{C}$ contains the electrophoretic profiles of the resolved contributions (components), matrix $\mathbf{S}^{\mathbf{T}}$ contains the corresponding mass spectra of the resolved contributions, and matrix $\mathbf{E}$ contains the residuals unexplained by the model.

In this study, the different samples were simultaneously analyzed and compared by MCR-ALS using the ROI column-wise augmented data matrix (Daug): 


$$
\mathrm{D}_{\mathrm{aug}}=\left[\begin{array}{c}
D_{1} \\
\vdots \\
D_{10}
\end{array}\right]=\left[\begin{array}{c}
C_{1} \\
\vdots \\
C_{10}
\end{array}\right] S^{\mathrm{T}}+\left[\begin{array}{c}
E_{1} \\
\vdots \\
E_{10}
\end{array}\right]=\mathrm{C}_{\mathrm{aug}} S^{\mathrm{T}}+\mathrm{E}_{\mathrm{aug}}
$$

This strategy allowed obtaining a common matrix of the mass spectra of the resolved components $\left(\mathbf{S}^{\mathbf{T}}\right)$ for all samples (ten components were selected in this study), and an augmented matrix describing the resolved electrophoretic profiles $\left(\mathbf{C}_{\mathbf{a u g}}\right)$ in every sample. These electrophoretic peaks resolved in matrix $\mathbf{C}_{\text {aug }}$ were allowed to vary in position (shifts) and shape among samples because the only requirement for a proper resolution is that the resolved mass spectra are the same for the common constituents in the different samples. This aspect is especially useful in the case of $\mathrm{CE}$ data where migration shifts among samples often occur and, hence, the alignment of electrophoretic peaks before analysis is not necessary $[17,23]$.

MCR-ALS analysis was carried out following standard procedures for the determination of the number of components (SVD) and initial estimates (pure variable detection method based on the SIMPLISMA algorithm) [19,20]. ALS optimization was performed under non-negativity constraints for electrophoretic $\left(\mathbf{C}_{\mathbf{a u g}}\right)$ and spectral $\left(\mathbf{S}^{\mathbf{T}}\right)$ profiles, and spectral normalization (equal height). All these tasks are incorporated in the MCR-ALS toolbox.

\subsubsection{Detection, identification and confirmation of antihypertensive peptides}

The mass spectra of the different MCR-ALS components contained in $\mathbf{S}^{\mathbf{T}}$ were searched for relevant compounds (features) (Fig. 1C). The mMass software 
(http://www.mmass.org/ [26]), which is an open-source mass spectrometry software, was used to automate feature selection and database search. Once imported the mass spectra of the different components to the mMass environment, only the ions with an intensity higher than $5 \%$ of the maximum intensity were considered as significant features for database search. This intensity threshold was low enough and close to the mass spectra background to ensure detection of the most relevant features in the mass spectra of the resolved MCR-ALS components.

An mMass database of antihypertensive peptides from milk proteins was built (see supplementary material for details) from the information collected after a "source search" with the keywords "milk" or "casein" in the on-line antihypertensive peptide database AHTPDB (http://crdd.osdd.net/raghava/ahtpdb/ [8]). The accurate experimental $\mathrm{m} / \mathrm{z}$ value $\left(\mathrm{m} / \mathrm{z}_{\text {ROI-MCR-ALS }}\right)$ of the significant features was searched in the lab-made mMmass database, considering different $[\mathrm{M}+\mathrm{zH}]^{\mathrm{z}+}$ ions, with $\mathrm{z}$ from +1 to +3 .

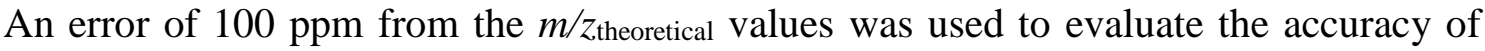
the identifications $\left(\mathrm{E}_{\mathrm{r}} \leq 100 \mathrm{ppm},\left|m / z_{\text {ROI-MCR-ALS }}-m / z_{\text {theoretical }}\right| / m / z_{\text {theoretical }} * 10^{6}\right)$. The tentative identifications were verified from the analysis of the raw mass spectra and extracted ion electropherograms (EIE) of the antihypertensive peptides, which were obtained with the MassHunter software, taking as a reference the $\mathrm{m} / \mathrm{z}$ value and the migration time of the MCR-ALS resolved components. BIOPEP [7] and MBPDB [9] databases were also used to validate and complement the information provided by AHTPDB [8] for the identified antihypertensive peptides.

The tentatively identified antihypertensive peptides were reliably confirmed by CEMS/MS comparing the experimental $\mathrm{m} / \mathrm{z}$ of the product ions observed in the tandem 
mass spectra with the theoretical $\mathrm{m} / \mathrm{z}$ of the peptide fragments generated by mMass following Biemann's nomenclature. Only the ions in the tandem mass spectra with an intensity higher than $5 \%$ of the maximum intensity were considered.

\section{Results and discussion}

\subsection{CE-MS}

In a previous study we used CE-MS in positive ESI mode for separation and identification of bioactive peptides in hypoallergenic infant milk formulas derived from bovine milk protein hydrolysates $[13,14]$. Sample clean-up and preconcentration using a citrate buffer with dithiothreitol (DTT) and urea followed by SPE with a C18 sorbent was applied before CE-MS. In CE-MS, an acidic BGE (1 M HAc (pH 2.3)) and sheath liquid hydroorganic solution (60:40 (v/v) propan-2-ol:water with 0.05\% (v/v) of HFor) resulted in excellent separation and detection of many low molecular mass bioactive peptides. These CE-MS conditions were used here for the analysis of the nutraceutical extracts, which contained approximately $9 \%(\mathrm{~m} / \mathrm{m})$ of hydrolyzed CSN proteins. The nutraceutical sample was simply prepared using hot water $\left(45^{\circ} \mathrm{C} / 1 \mathrm{~h}\right)$ as extractant $[13,14,24]$, because we wanted to minimize the sample pretreatment. Furthermore, the nutraceutical extract, after centrifugation and filtration, was a transparent solution that could be directly analyzed by CE-MS without further clean-up, in contrast to the milklike emulsions obtained after adding hot water to the hypoallergenic infant milk formulas $[13,14]$. Fig. 2A shows the typical total ion electropherogram (TIE) by CE-MS for the nutraceutical extract. As can be observed, the nutraceutical extract presented a characteristic and complex electrophoretic profile with multiple compounds comigrating 
between 7 and $20 \mathrm{~min}$ in several electrophoretic peaks of different intensities. To facilitate, speed-up and systematize data analysis, it was applied a workflow (Fig. 1) based on advanced chemometric tools that includes data pre-processing, resolution, feature finding and identification of antihypertensive peptides.

\subsection{Data analysis}

The data analysis workflow was applied to the dataset generated from the raw CE-MS electropherograms obtained for the analysis of the different independent nutraceutical extracts. The ROI search resulted in a great reduction of the $\mathrm{m} / \mathrm{z}$ dimension (columns) of the input full resolution data matrix, from $171798 \mathrm{~m} / \mathrm{z}$ values (raw CE-MS data, Fig. 1A) until $954 \mathrm{~m} / \mathrm{z}$ ROIs (CE-MS-ROI compressed data, Fig. 1A). The comparison of Fig. 2A and 2B shows a good agreement between the raw TIE and the detected ROIs for a typical nutraceutical extract (sample 1), suggesting the reliability of the compression. The ROI compression is a very efficient untargeted $\mathrm{m} / \mathrm{z}$ peaking algorithm based on detection of relevant electrophoretic peaks above a certain intensity threshold. In contrast to the binning compression method, it does not arbitrarily skew $\mathrm{m} / \mathrm{z}$ accuracy [17]. ROI compression greatly decreases the memory and computing requirements needed later for resolution by MCR-ALS with such complex data sets.

MCR-ALS was applied to the column-wise augmented data matrix containing simultaneously the ROI-compressed data matrices of all the nutraceutical extracts. MCR-ALS resolved the electropherogram profiles and mass spectra of the common nutraceutical components in the different extracts (Fig. 1B). Ten components allowed explaining a high percentage of variance $\left(\mathrm{R}^{2}=94.8 \%\right)$, with an acceptable lack-of-fit 
value $(\mathrm{LOF}=22.9 \%)$. These figures of merits did not substantially improve if the number of components was increased, for example, until $25 \quad\left(\mathrm{R}^{2}=97.6 \%\right.$ and $\mathrm{LOF}=15.3 \%$ ), and ten components were selected to avoid fitting non-systematic or residual data variance. Fig. 3 shows the typical electrophoretic profiles of the 10 resolved components for the nutraceutical extract (sample 1), which agreed to a large extent with the most relevant $954 \mathrm{~m} / z$ ROIs detected after data compression (Fig. 2B). Table 1 shows the average relative area of the different components (\%Area) calculated from the values obtained for the electrophoretic profiles of the different extracts. This area gives a rough idea of the total concentration of the compounds in the MCR-ALS resolved components, but being aware that the relation between the MS signal and the concentration may vary notably between the different compounds, even between those from the same structural family (e.g. peptides). The mass spectra of the components were screened for relevant features. Only the mass spectra ions with a relative intensity (\%Intensity) higher than $5 \%$ of the maximum intensity were considered as significant features for the targeted database mass search. The mMass MS software was used in the last part of the data analysis workflow because it allowed processing, as line mass spectra, the mass spectra of the components directly exporting from MATLAB in text format [26]. Furthermore, mMass had many other interesting features for this study related to peptide sequence editing, molecular formula generation, accurate molecular mass and $m / z$ calculation, database building and search.

Table 1 shows the 22 antihypertensive peptides tentatively identified in the nutraceutical extract after database search and comparison of the raw EIE and mass spectra with the corresponding MCR-ALS component profiles and mass spectra. Fig. 4 shows as an example this confirmatory comparison for some of the peptides. As can be observed, the 
agreement between the raw EIE (Fig. 4A) and the MCR-ALS components (Fig. 4B) was good. Regarding the zoomed regions of the mass spectra shown as insets, the MCRALS mass spectra showed a smaller number of ions in some of the cases because the comigrating compounds were resolved in different components (e.g. compare Fig. 4A-ii and B-ii). As can be observed in Table 1, as the nutraceutical was prepared from hydrolyzed casein proteins $(9 \%(\mathrm{~m} / \mathrm{m}))$, all the identified antihypertensive peptides corresponded to bovine CSN fragments, from 2 to 15 amino acids. Furthermore, in general, they were found at low concentration, as can be observed by the \%Area of the different components and the \%Intensity of the detected ions. The half maximal inhibitory concentration (IC50) for angiotensin-converting enzyme (ACE) was reported for some of the peptides, and ranged from $1.7 \mu \mathrm{M}$ for the most bioactive peptide (SKVYPFPGPI) until $2439 \mu \mathrm{M}$ for the least (RL). In addition to the antihypertensive activity, some peptides were also reported to be dipeptidyl peptidase IV inhibitors (DPP IV inhibitor), and hence relevant for diabetes mellitus type 2 treatment, and another DPP IV inhibitor, antioxidative, renin inhibitor, calmodulin-dependent cyclic nucleotide phosphodiesterase (CaMPDE) inhibitor. All the antihypertensive peptides were reported in AHTPDB database [8], which in our opinion is the most comprehensive antihypertensive peptide database of the three investigated in this study. Anyway, it is always recommended crosschecking the information for the identified peptides in AHTPDB database with BIOPEP [7] and MBPDB [9] databases, as well as with the original references cited in the databases. Furthermore, it is necessary to use a specialized MS software such as mMass to ensure accurate molecular mass and $\mathrm{m} / \mathrm{z}$ calculations [26]. 
Regarding the accuracy of the identifications, an error $\left(\mathrm{E}_{\mathrm{r}}\right)$ of $100 \mathrm{ppm}$ from the

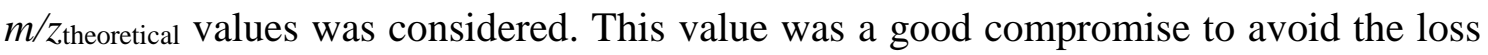
of potential identifications, because $\mathrm{E}_{\mathrm{r}}$ was measured on the mass spectra of the different MCR-ALS components, which were resolved considering all the nutraceutical extracts. As can be observed, the mass spectra shown as insets in Fig. 4A-i-iii and B-iiii show some differences in the $\mathrm{m} / \mathrm{z}$ values of the ions between the experimental and the MCR-ALS mass spectra.

In order to reliably confirm the identity of the peptide candidates, targeted CE-MS/MS experiments were performed. Table S-1 shows the selected precursor ions and the detected product ions for the tentatively identified antihypertensive peptides of Table 1. The identity of 17 antihypertensive peptides was confirmed (highlighted in bold in Table 1 and Table S-1) from the tandem mass spectra fragmentation patterns. As an example, Fig. S-1 shows the EIE, the mass spectrum, the tandem mass spectrum and the peptide fragments obtained for the antihypertensive peptide DKIHPF $\left(\mathrm{m} / \mathrm{z}_{\text {theoretical }}=\right.$ 378.7056, $\mathrm{z}=+2$ ). The identity of 5 peptides could not be confirmed by CE-MS/MS (Table 1 and Table S-1). VLNENL, IP/LP and PL peptides were not detected due to the lower sensitivity of the IT mass spectrometer when compared to the TOF mass spectrometer. Only the identity of the ENLLRF peptide could not be confirmed because the product ions in the MS/MS spectra did not match with the expected fragmentation pattern. This low false identification rate suggested the validity of the accurate mass and high resolution TOF mass spectrometer for the straightforward and inexpensive untargeted screening of antihypertensive peptides. The number of confirmed antihypertensive peptides was high, considering the low content of hydrolyzed casein proteins in the nutraceutical and the very simple sample pretreatment. In general, these 
results suggest the great potential of the proposed analytical methodology for the simple, rapid and systematic analysis of bioactive peptides in nutraceuticals and milk derived functional foods, as part of quality control, food safety and fraud control programs. More broadly, it could be adapted to similar untargeted and targeted CE-MS and LC-MS analysis in other foodomics research areas.

\section{Acknowledgements}

This study was supported by a grant from Spanish Ministry of Economy and Competitiveness (CTQ2014-56777-R) and the Cathedra UB Rector Francisco Buscarons Ubeda (Forensic Chemistry and Chemical Engineering). Roger Pero-Gascon acknowledges the same Ministry for a FPU fellowship. We also thank Karen Martí for her collaboration in part of this study.

The authors have declared no conflict of interest. 


\section{References}

[1] S. Séverin, X. Wenshui, Milk biologically active components as nutraceuticals: review, Crit. Rev. Food Sci. Nutr. 45 (2005) 645-56. doi:10.1080/10408690490911756.

[2] D. Martinez-Ledesma, B. Miralles, I. Recio, B. Hernández-Ledesma, Antihypertensive peptides from food proteins, Food Funct. 3 (2012) 350-61. doi:10.1039/C2FO10192K.

[3] M. Hajfathalian, S. Ghelichi, P.J. García-Moreno, A.-D. Moltke Sørensen, C. Jacobsen, Peptides: production, bioactivity, functionality, and applications., Crit. Rev. Food Sci. Nutr. (2017) 1-33. doi:10.1080/10408398.2017.1352564.

[4] Y. Liu, M. Pischetsrieder, Identification and relative quantification of bioactive peptides sequentially released during simulated gastrointestinal digestion of commercial kefir, J. Agric. Food Chem. 65 (2017) 1865-1873. doi:10.1021/acs.jafc.6b05385.

[5] X. Fan, L. Bai, L. Zhu, L. Yang, X. Zhang, Marine algae-derived bioactive peptides for human nutrition and health, J. Agric. Food Chem. 62 (2014) 921122. doi:10.1021/jf502420h.

[6] S.Y. Lee, S.J. Hur, Antihypertensive peptides from animal products, marine organisms, and plants, Food Chem. 228 (2017) 506-17.

doi:10.1016/j.foodchem.2017.02.039.

[7] P. Minkiewicz, J. Dziuba, A. Iwaniak, M. Dziuba, M. Darewicz, BIOPEP database and other programs for processing bioactive peptide sequences, $\mathrm{J}$. AOAC Int. 91 (2008) 965-80.

[8] R. Kumar, K. Chaudhary, M. Sharma, G. Nagpal, J.S. Chauhan, S. Singh, A. Gautam, G.P.S. Raghava, AHTPDB: a comprehensive platform for analysis and presentation of antihypertensive peptides, Nucleic Acids Res. 43 (2015) D95662. doi:10.1093/nar/gku1141.

[9] S.D. Nielsen, R.L. Beverly, Y. Qu, D.C. Dallas, Milk bioactive peptide database: a comprehensive database of milk protein-derived bioactive peptides and novel visualization, Food Chem. 232 (2017) 673-82. doi:10.1016/j.foodchem.2017.04.056.

[10] P.B. Kunda, F. Benavente, S. Catalá-Clariana, E. Giménez, J. Barbosa, V. SanzNebot, Identification of bioactive peptides in a functional yogurt by micro liquid chromatography time-of-flight mass spectrometry assisted by retention time prediction, J. Chromatogr. A. 1229 (2012) 121-8. doi:10.1016/j.chroma.2011.12.093.

[11] J. Giacometti, A. Buretić-Tomljanović, Peptidomics as a tool for characterizing bioactive milk peptides, Food Chem. 230 (2017) 91-8. doi:10.1016/j.foodchem.2017.03.016.

[12] A.L. Capriotti, C. Cavaliere, S. Piovesana, R. Samperi, A. Laganà, Recent trends in the analysis of bioactive peptides in milk and dairy products, Anal. Bioanal. Chem. 408 (2016) 2677-2685. doi:10.1007/s00216-016-9303-8.

[13] S. Català-Clariana, F. Benavente, E. Giménez, J. Barbosa, V. Sanz-Nebot, Identification of bioactive peptides in hypoallergenic infant milk formulas by capillary electrophoresis-mass spectrometry, Anal. Chim. Acta. 683 (2010) 11925. doi:doi:10.1016/j.aca.2010.10.002.

[14] S. Català-Clariana, F. Benavente, E. Giménez, J. Barbosa, V. Sanz-Nebot, 
Identification of bioactive peptides in hypoallergenic infant milk formulas by CE-TOF-MS assisted by semiempirical model of electromigration behavior, Electrophoresis. 34 (2013) 1886-94. doi:10.1002/elps.201200547.

[15] C. Ibáñez, T. Acunha, A. Valdes, V. Garcia-Cañas, A. Cifuentes, C. Simo, Capillary electrophoresis in food and foodomics, in: P. Schmitt-Kopplin (Ed.), Methods Mol. Biol., Humana Press, New York, 2016: pp. 471-507. doi:10.1007/978-1-4939-6403-1_22.

[16] D. Heiger, High performance capillary electrophoresis. An introduction, Agilent Technologies, Germany, 2000. doi:10.1039/9781847550521-00208.

[17] E. Gorrochategui, J. Jaumot, S. Lacorte, R. Tauler, Data analysis strategies for targeted and untargeted LC-MS metabolomic studies: overview and workflow, TrAC - Trends Anal. Chem. 82 (2016) 425-42. doi:10.1016/j.trac.2016.07.004.

[18] E. Gorrochategui, J. Jaumot, R. Tauler, A protocol for LC-MS metabolomic data processing using chemometric tools, Protoc. Exch. (2015) 1-27. Accessed on November 13, 2017. doi:10.1038/protex.2015.102.

[19] J. Jaumot, R. Gargallo, A. de Juan, R. Tauler, A graphical user-friendly interface for MCR-ALS: a new tool for multivariate curve resolution in MATLAB, Chemom. Intell. Lab. Syst. 76 (2005) 101-10. doi:10.1016/j.chemolab.2004.12.007.

[20] J. Jaumot, A. de Juan, R. Tauler, MCR-ALS GUI 2.0: New features and applications, Chemom. Intell. Lab. Syst. 140 (2015) 1-12. doi:10.1016/j.chemolab.2014.10.003.

[21] E. Ortiz-Villanueva, J. Jaumot, F. Benavente, B. Piña, V. Sanz-Nebot, R. Tauler, Combination of CE-MS and advanced chemometric methods for high-throughput metabolic profiling, Electrophoresis. 36 (2015) 2324-35. doi:10.1002/elps.201500027.

[22] L. Pont, F. Benavente, J. Jaumot, R. Tauler, J. Alberch, S. Ginés, J. Barbosa, V. Sanz-Nebot, Metabolic profiling for the identification of Huntington biomarkers by on-line solid-phase extraction capillary electrophoresis mass spectrometry combined with advanced data analysis tools, Electrophoresis. 37 (2016) 795-808. doi:10.1002/elps.201500378.

[23] E. Ortiz-Villanueva, F. Benavente, B. Piña, V. Sanz-Nebot, R. Tauler, J. Jaumot, Knowledge integration strategies for untargeted metabolomics based on MCRALS analysis of CE-MS and LC-MS data, Anal. Chim. Acta. 978 (2017) 10-23. doi:10.1016/j.aca.2017.04.049.

[24] M. Plaza, C. Turner, Pressurized hot water extraction of bioactives, Trends Anal. Chem. 76 (2017) 53-82. doi:10.1016/bs.coac.2016.12.005.

[25] M. Borges-Alvarez, F. Benavente, E. Giménez, J. Barbosa, V. Sanz-Nebot, Assessment of capillary electrophoresis TOF MS for a confident identification of peptides, J. Sep. Sci. 33 (2010) 2489-98. doi:10.1002/jssc.201000361.

[26] M. Strohalm, M. Hassman, B. Kosata, M. Kodicek, mMass data miner: an open source alternative for mass spectrometric data analysis, Rapid Commun. Mass Spectrom. 22 (2008) 905-8. doi:10.1002/rcm. 
A) Data pre-processing: ROI compression and data arrangement

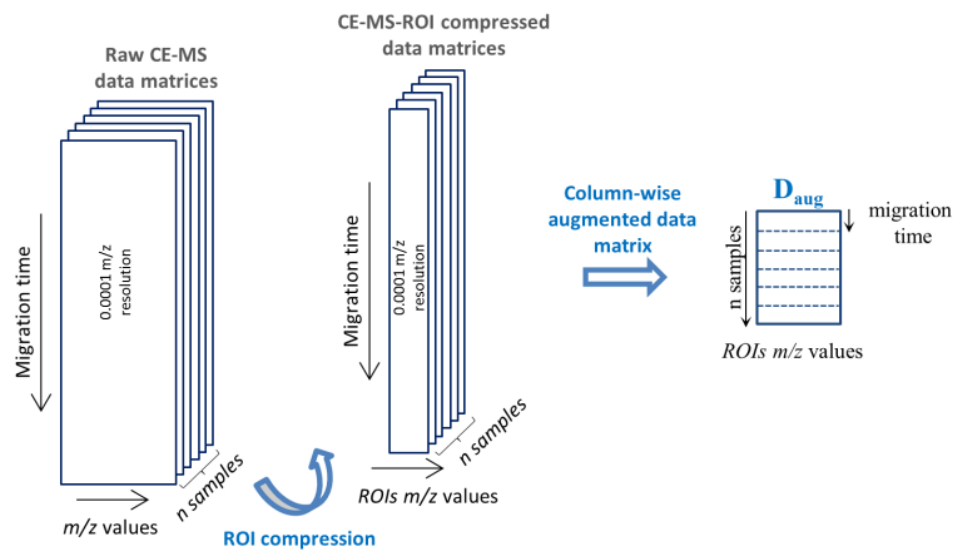

B) Data resolution: MCR-ALS

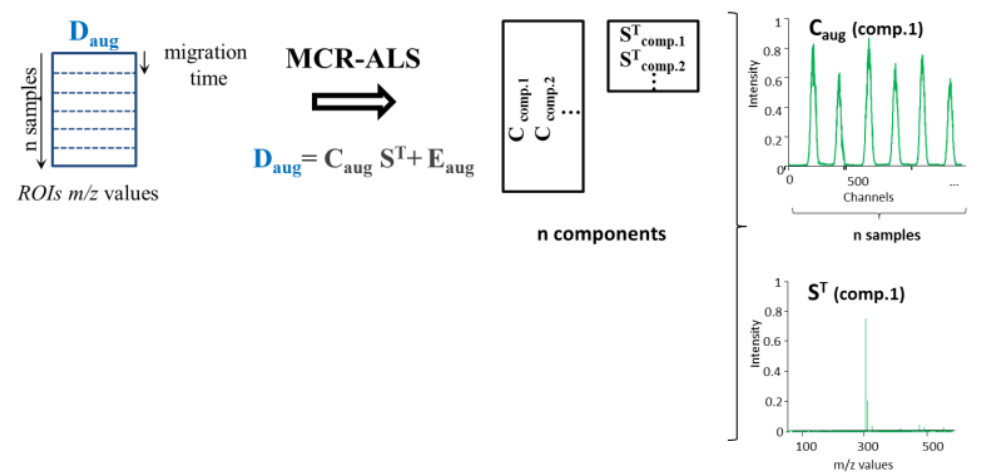

C) Feature finding, identification and confirmation of antihypertensive peptides

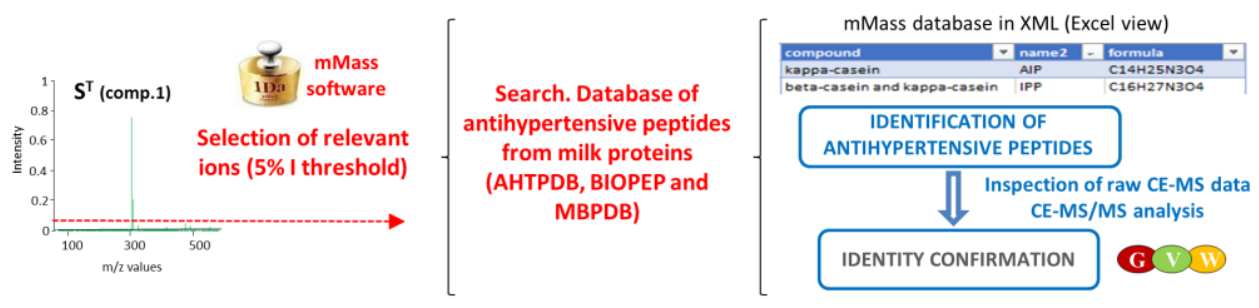

Figure 1. Data analysis workflow: (A) data pre-processing, (B) data resolution and (C)

feature finding, identification and confirmation of antihypertensive peptides. 

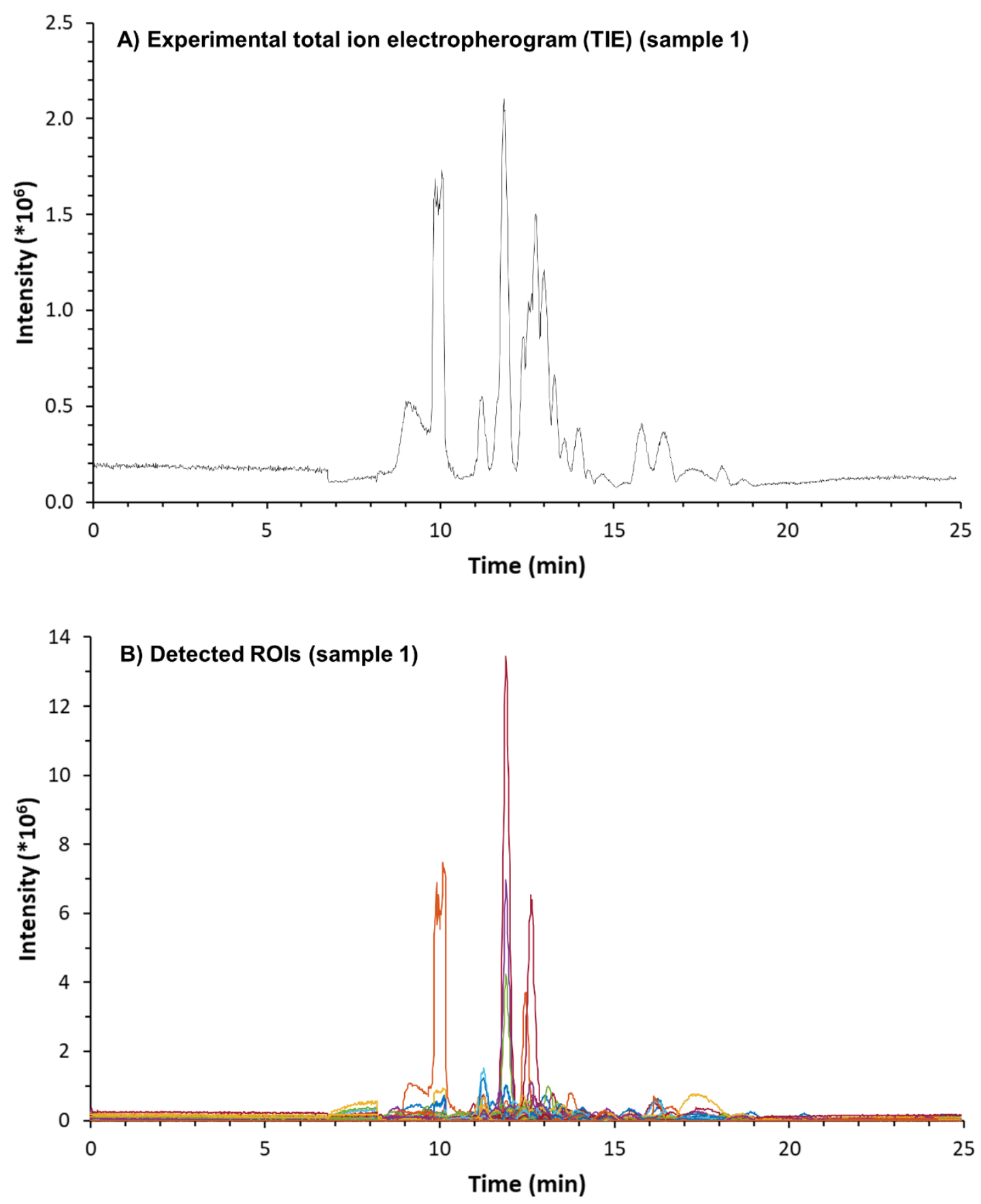

Figure 2. (A) Experimental total ion electropherogram (TIE) and (B) detected regions of interest (ROI) for the nutraceutical extract sample 1 (each colour trace stands for a ROI with a different $m / z$ value in sample 1 . No colour legend is shown because of the large number of ROIs). 


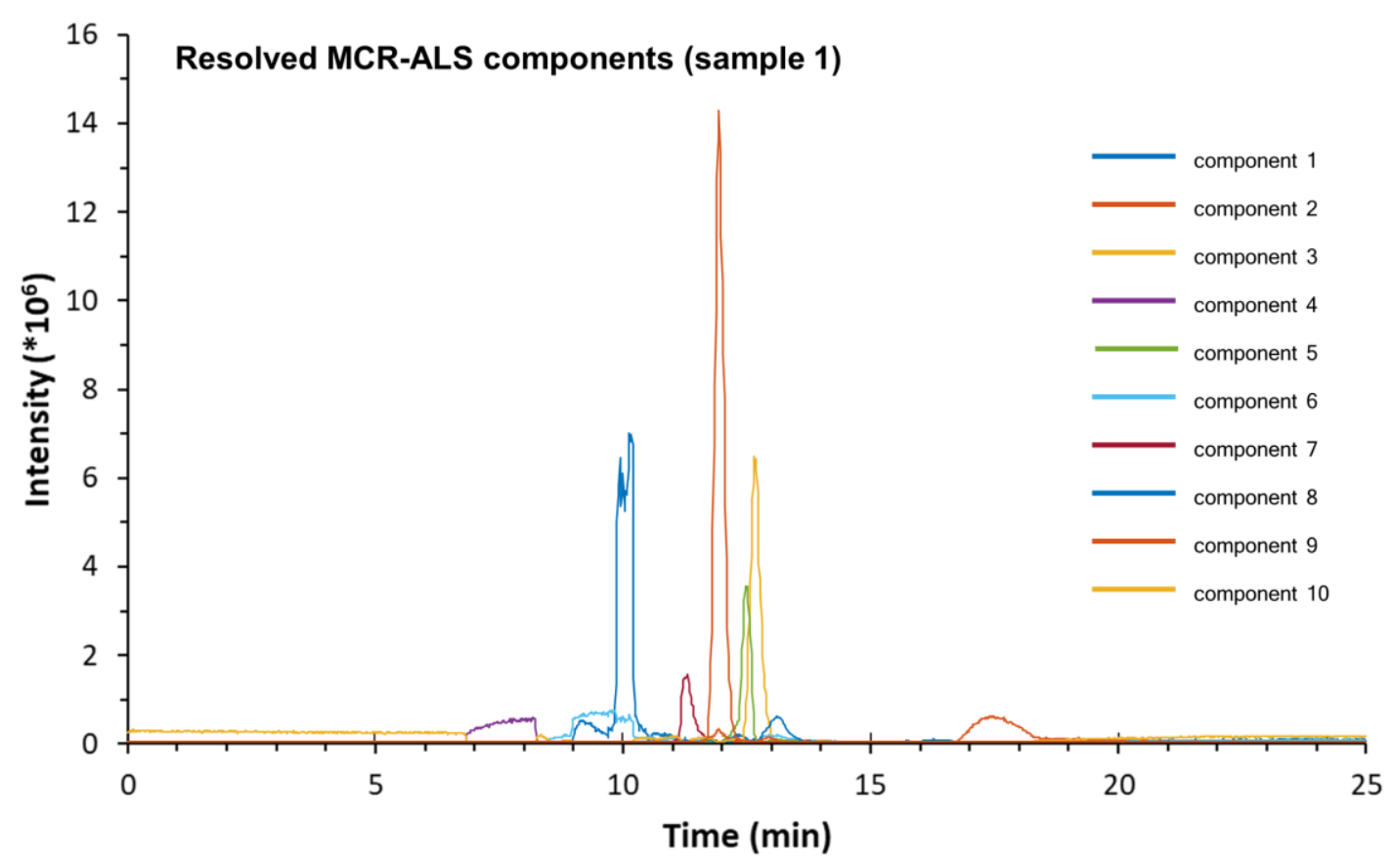

Figure 3. Resolved components by multivariate curve resolution alternating least squares (MCR-ALS) for the nutraceutical extract sample 1 (each colour trace stands for one of the 10 characteristic resolved components in sample 1). 


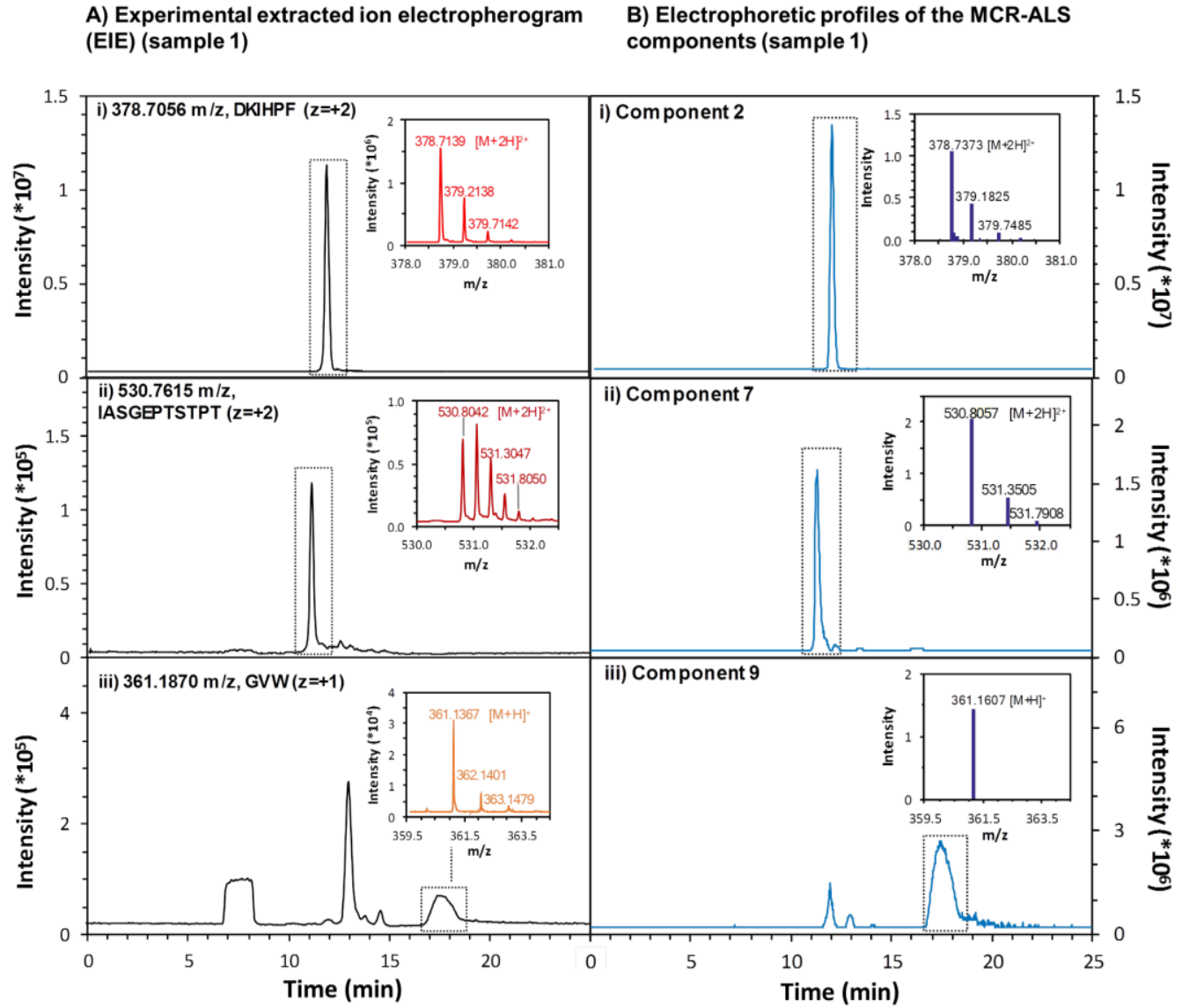

Figure 4. (A) Experimental extracted ion electropherogram (EIE) and (B) corresponding multivariate curve resolution alternating least squares (MCR-ALS) resolved component for the nutraceutical extract sample 1. The tentatively identified antihypertensive peptides are i) DKIHPF $\left(m / z_{\text {theoretical }}=378.7056, \quad \mathrm{z}=+2\right)$, ii) IASGEPTSTPT $\left(m / z_{\text {theoretical }}=530.7615, \mathrm{z}=+2\right)$ and iii $)$ GVW $\left(m / z_{\text {theoretical }}=361.1870\right.$, $\mathrm{Z}=+1)$. 
Table 1. Antihypertensive peptides tentatively identified in the mass spectra of the resolved MCR-ALS components of the nutraceutical extract after database search. All peptides were confirmed by comparison of the experimental CE-MS with the MCR-ALS data (CSN=casein).

\begin{tabular}{|c|c|c|c|c|c|c|c|c|c|c|c|c|}
\hline \multicolumn{2}{|c|}{ MCR-ALS component } & \multicolumn{11}{|c|}{ Antihypertensive peptides ${ }^{\mathrm{a}}$} \\
\hline Number & $\begin{array}{c}\text { \%Area } \\
\text { (an average in } \\
\text { the profiles) }\end{array}$ & $\underset{\text { ROI-MRC-ALS }}{\mathbf{m} / \mathbf{z}}$ & $\begin{array}{c}\mathbf{m} / \mathbf{z} \\
\text { theoretical }\end{array}$ & $\mathbf{E}_{\mathbf{r}}(\mathbf{m} / \mathbf{z})$ & $\mathbf{E}_{\mathbf{r}}(\mathbf{p p m})$ & $\mathbf{z}$ & $\begin{array}{l}\text { \%Intensity (in the } \\
\text { spectra of the MCR- } \\
\text { ALS components) }\end{array}$ & Sequence & Bovine milk CSN protein & $\begin{array}{c}\text { IC50 (ACE, } \\
\mu \mathrm{M})\end{array}$ & Databases $^{\text {b }}$ & $\begin{array}{l}\text { Confirmed by } \\
\text { CE-MS/MS }\end{array}$ \\
\hline 1 & 32.5 & 203.1408 & 203.1390 & 0.0018 & 8.8 & 1 & 22 & IA & kappa-CSN & $153^{\mathrm{c}}$ (soybean) & AHTPDB and BIOPEP & $x$ \\
\hline 2 & 13.5 & 378.7373 & 378.7056 & 0.0317 & 84 & 2 & 100 & DKIHPF & beta-CSN & 257 & $\begin{array}{l}\text { AHTPDB, BIOPEP and } \\
\text { MBPDB } \\
\end{array}$ & $\checkmark$ \\
\hline \multirow{2}{*}{3} & \multirow{2}{*}{6.0} & 396.2342 & 396.2241 & 0.0101 & 25 & 2 & 8.3 & ENLLRF & alpha-CSN & $\begin{array}{c}82 \\
\text { (caprine milk) }\end{array}$ & AHTPDB and MBPDB & $x$ \\
\hline & & 796.4355 & 796.4240 & 0.0115 & 14 & 1 & 7.0 & YIPIQY & kappa-CSN & $\begin{array}{c}10 \\
\text { (ovine milk) } \\
\end{array}$ & $\begin{array}{c}\text { AHTPDB, BIOPEP and } \\
\text { MBPDB } \\
\end{array}$ & $\checkmark$ \\
\hline 4 & 2.5 & 701.4156 & 701.3828 & 0.0328 & 47 & 1 & 33 & VLNENL & alpha-CSN & - & AHTPDB & $x$ \\
\hline 5 & 3.4 & 552.8019 & 552.8080 & -0.0062 & -11 & 2 & 18 & SKVYPFPGPI & $\begin{array}{c}\text { beta-CSN (sequence conflict } \\
\text { SLVYYPPGPI) }\end{array}$ & 1.7 & AHTPDB and BIOPEP & $\checkmark$ \\
\hline 6 & 12.2 & - & - & - & - & - & & - & - & - & - & - \\
\hline \multirow{8}{*}{7} & \multirow{8}{*}{2.0} & \multirow{2}{*}{276.1533} & \multirow{2}{*}{276.1554} & \multirow{2}{*}{-0.0021} & \multirow{2}{*}{-7.7} & \multirow{2}{*}{1} & \multirow{2}{*}{10} & EK & alpha-CSN, beta-CSN and kappa-CSN & $-\mathrm{c}$ & \multirow{2}{*}{ AHTPDB and BIOPEP } & $\checkmark$ \\
\hline & & & & & & & & KE & alpha-CSN and beta-CSN & - & & $\checkmark$ \\
\hline & & \multirow{2}{*}{288.2096} & \multirow{2}{*}{288.2030} & \multirow{2}{*}{0.0066} & \multirow{2}{*}{23} & \multirow{2}{*}{1} & \multirow{2}{*}{29} & IR & kappa-CSN & $695^{\mathrm{e}}$ & \multirow{2}{*}{ AHTPDB and BIOPEP } & $\checkmark$ \\
\hline & & & & & & & & RL & alpha-CSN & 2439 & & $\checkmark$ \\
\hline & & \multirow{2}{*}{322.1815} & \multirow{2}{*}{322.1874} & \multirow{2}{*}{-0.0059} & \multirow{2}{*}{-18} & \multirow{2}{*}{1} & \multirow{2}{*}{13} & FR & alpha-CSN & $\begin{array}{l}920^{\mathrm{c}} \text { (sake } \\
\text { lees) }\end{array}$ & \multirow{2}{*}{ AHTPDB and BIOPEP } & $\checkmark$ \\
\hline & & & & & & & & RF & kappa-CSN & 93 (sake lees) & & $\checkmark$ \\
\hline & & 530.8057 & 530.7615 & 0.0442 & 83 & 2 & 22 & IASGEPTSTPT & kappa-CSN & - & АHTPDB & $\checkmark$ \\
\hline & & 580.0036 & 579.9734 & 0.0302 & 52 & 3 & 8.9 & KYPVQPFTESQSLTL & beta-CSN & 44 & АHTPDB & $\checkmark$ \\
\hline \multirow{7}{*}{8} & \multirow{7}{*}{1.8} & 2901514 & 2001517 & 00006 & 30 & 1 & 12 & $\mathrm{IP} / \mathrm{LP}^{\mathrm{d}}$ & alpha-CSN, beta-CSN and kappa-CSN & $130^{\mathrm{c}} / \mathrm{-}^{\mathrm{c}}$ & \multirow{2}{*}{$\begin{array}{l}\text { AHTPDB, BIOPEP and } \\
\text { MBPDB }\end{array}$} & $x$ \\
\hline & & $225.15+1$ & $22 \% .15+1$ & -0.0000 & - & 1 & 10 & $P^{d}$ & alpha-CSN and beta-CSN & $-\mathrm{c}$ & & $x$ \\
\hline & & 246.1622 & 246.1561 & 0.0061 & 25 & 1 & 37 & $\mathbf{A R}$ & kappa-CSN & 95.5 & AHTPDB and BIOPEP & $\checkmark$ \\
\hline & & 318.1715 & 318.1812 & -0.0097 & -30 & 1 & 8.8 & LW & alpha-CSN & $15^{\mathrm{f}}$ & $\begin{array}{c}\text { AHTPDB, BIOPEP and } \\
\text { MBPDB } \\
\end{array}$ & $\checkmark$ \\
\hline & & 335.1816 & 335.2148 & -0.0332 & -99 & 3 & 12 & LKKYKVPQ & alpha-CSN & - & AHTPDB & $\checkmark$ \\
\hline & & 342.2635 & 342.2387 & 0.0247 & 72 & 1 & 14 & IPI & kappa-CSN & - & AHTPDB & $\checkmark$ \\
\hline & & 867.451 & 867.5298 & -0.0788 & -91 & 1 & 11 & SKVLPVPQ & beta-CSN & 39 & AHTPDB and MBPDB & $\checkmark$ \\
\hline 9 & 4.0 & 361.1607 & 361.1870 & -0.0264 & -73 & 1 & 58 & GVW & alpha-CSN (sequence conflict GAW) & 240 & AHTPDB and BIOPEP & $\checkmark$ \\
\hline 10 & 21.9 & - & - & - & - & - & - & - & - & - & - & - \\
\hline
\end{tabular}


a)All the peptides are bovine CSN fragments. Most of them were reported after enzymatic hydrolysis of milk, dairy products and purified CSNs of bovine origin, excepting otherwise indicated. ${ }^{b}$ The peptide sequence from bovine CSN in the peptide databases differ from the most typical bovine CSN proteoform reported in Uniprot knowledgebase (www.uniprot.org).

${ }^{\text {c) }}$ This peptide was also dipeptidyl peptidase IV inhibitor (DPP IV inhibitor).

${ }^{\mathrm{d}}$ These peptides cannot be differenced from their MS/MS fragmentation patterns.

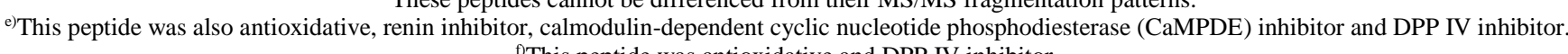
${ }^{f}$ This peptide was antioxidative and DPP IV inhibitor. 


\section{Supporting Information}

\section{Table of contents}

Building the mMass database of antihypertensive peptides

from milk proteins

Table S-1. CE-MS/MS confirmation of the antihypertensive peptides

Figure S-1. CE-MS/MS confirmation of the antihypertensive peptide DKIHPF 


\section{Building the mMass database of antihypertensive peptides from milk proteins}

The mMass database of antihypertensive peptides from milk proteins was built from the information collected after a "source search" with the keywords "milk" or "casein" in the on-line antihypertensive peptide database AHTPDB (http://crdd.osdd.net/raghava/ahtpdb/ [8]). A tab-delimited text file with the AHTPDB database ID number, the source and the one letter code sequence of the antihypertensive peptides was saved in Microsoft Excel 2016, and converted to FASTA format using a freely available on-line application (http://sequenceconversion.bugaco.com/converter/biology/sequences/tab_to_fasta.php).

The FASTA file was imported into mMass to generate the molecular formulas of the different peptide sequences, which later were used to calculate the accurate monoisotopic molecular mass and the accurate $\mathrm{m} / \mathrm{z}$ values of differently charged molecular ions $\left(\mathrm{m} / \mathrm{z}_{\text {theoretical }}\right)$. The Excel file with the AHTPDB database ID, the source and the sequence was completed with the molecular formulas obtained by mMass from the imported FASTA file. Then, the Excel file was given the appropriate XML format using as an XML origin one of the default databases available in mMass (e.g. compounds.xml). Finally the Excel file was exported as an XML file ready to use as a database in mMass. 
Table S-1. CE-MS/MS confirmation of the antihypertensive peptides identified in the mass spectra of the resolved MCR-ALS components of the nutraceutical extract after database search.

a) These peptides cannot be differenced by their MS/MS fragmentation patterns.

\begin{tabular}{|c|c|c|c|c|c|c|c|}
\hline \multirow{2}{*}{$\begin{array}{l}\text { MCR-ALS } \\
\text { Component }\end{array}$} & \multicolumn{2}{|c|}{ Precursor ion } & \multicolumn{2}{|c|}{ Antihypertensive peptides } & \multicolumn{3}{|c|}{ Product ions } \\
\hline & $\overline{\mathbf{m} / \mathbf{z}_{\text {experimental }}}$ & $\overline{\mathbf{z}}$ & $\overline{\mathbf{m} / \mathbf{z}_{\text {theoretical }}}$ & Sequence & $\overline{\mathbf{m} / \mathbf{z}_{\text {experimental }}}$ & $\overline{Z z}$ & "Sequence \\
\hline 1 & 203.1 & 1 & 203.1 & IA & - & - & - \\
\hline \multirow{5}{*}{2} & \multirow{5}{*}{378.7} & \multirow{5}{*}{2} & \multirow{5}{*}{378.8} & \multirow{5}{*}{ DKIHPF } & 513.3 & 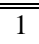 & $\mathrm{y}_{4}$ \\
\hline & & & & & 494.3 & 1 & $\mathrm{~b}_{4}$ \\
\hline & & & & & 369.8 & 2 & $\mathrm{M}-\mathrm{H}_{2} \mathrm{O}$ \\
\hline & & & & & 321.2 & 2 & $\mathrm{y}_{5}$ \\
\hline & & & & & 263.2 & 1 & $\mathrm{y}_{2}$ \\
\hline \multirow{5}{*}{3} & 396.2 & 2 & 396.2 & 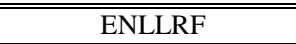 & - & - & - \\
\hline & \multirow{4}{*}{796.4} & \multirow{4}{*}{1} & \multirow{4}{*}{796.4} & \multirow{4}{*}{ YIPIQY } & 779.9 & 1 & $\mathrm{M}-\mathrm{NH}_{3}$ \\
\hline & & & & & 778.9 & 1 & $\mathrm{M}-\mathrm{H}_{2} \mathrm{O}$ \\
\hline & & & & & 615.7 & 1 & b5 \\
\hline & & & & & 374.5 & 1 & b3 \\
\hline 4 & 701.4 & 1 & 701.4 & VLNENL & - & 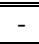 & - \\
\hline \multirow{6}{*}{5} & \multirow{6}{*}{552.8} & & & & 501.2 & 2 & $\overline{\mathrm{Z}_{9}}$ \\
\hline & & & & & 473.3 & 2 & $\mathrm{a}_{9}$ \\
\hline & & & & & 437.1 & 2 & $\mathrm{Z}_{8}$ \\
\hline & & 2 & 552.8 & SKVYPFPGPI & 387.4 & 2 & $\mathrm{z}_{7}$ \\
\hline & & & & & 312.1 & 1 & $\mathrm{X}_{3}$ \\
\hline & & & & & 216.1 & 1 & $\mathrm{~b}_{2}$ \\
\hline 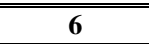 & - & - & - & - & - & - & - \\
\hline & & & & EK & 258.2 & 1 & $\overline{\mathrm{M}-\mathrm{H}_{2} \mathrm{O}}$ \\
\hline & 276.2 & 1 & 276.2 & KE & 258.2 & 1 & $\mathrm{M}-\mathrm{H}_{2} \mathrm{O}$ \\
\hline & & & & & 271.2 & 1 & M-NH 3 \\
\hline & & & & IR & 270.2 & 1 & $\mathrm{M}-\mathrm{H}_{2} \mathrm{O}$ \\
\hline & & & & & 175.1 & 1 & $\mathrm{y}_{1}$ \\
\hline & 288.1 & 1 & 288.2 & & 271.2 & 1 & $\mathrm{M}-\mathrm{NH}_{3}$ \\
\hline & & & & $\mathbf{R L}$ & 270.2 & 1 & $\mathrm{M}-\mathrm{H}_{2} \mathrm{O}$ \\
\hline & & & & & 157.1 & 1 & $\mathrm{~b}_{1}$ \\
\hline & & & & & 305.2 & 1 & $\mathrm{M}-\mathrm{NH}_{3}$ \\
\hline & & & & FR & 304.2 & 1 & $\mathrm{M}-\mathrm{H}_{2} \mathrm{O}$ \\
\hline 7 & 3223 & & 3220 & & 175.1 & 1 & $\mathrm{y}_{1}$ \\
\hline & 322.3 & 1 & 322.2 & & 305.2 & 1 & $\mathrm{M}-\mathrm{NH}_{3}$ \\
\hline & & & & $\mathbf{R F}$ & 304.2 & 1 & $\mathrm{M}-\mathrm{H}_{2} \mathrm{O}$ \\
\hline & & & & & 157.1 & 1 & $\mathrm{~b}_{1}$ \\
\hline & & & & & 760.4 & 1 & $\mathrm{c}_{8}$ \\
\hline & 530.8 & 2 & 530.8 & IASGEPTSTPT & 638.5 & 1 & $\mathrm{~b}_{7}-\mathrm{H}_{2} \mathrm{O}$ \\
\hline & & & & & 217.1 & 1 & $\mathrm{y}_{2}$ \\
\hline & & & & & 433.2 & 1 & $\mathrm{y}_{4}$ \\
\hline & 580.1 & 3 & 580.0 & KYPVQPFTESQSLTL & 418.1 & 3 & $\mathrm{y}_{11}$ \\
\hline & & & & & 416.1 & 1 & $\mathrm{z}_{4}$ \\
\hline & 2292 & 1 & 2292 & $\overline{\mathrm{IP} / \mathrm{LP}^{\mathrm{a}}}$ & - & - & - \\
\hline & 229.2 & & 229.2 & PL & - & - & - \\
\hline & 2462 & 1 & 2462 & $\mathbf{P}$ & 229.1 & 1 & $\mathrm{M}-\mathrm{NH}_{3}$ \\
\hline 8 & 240.2 & 1 & 240.2 & AR & 228.1 & 1 & $\mathrm{M}-\mathrm{H}_{2} \mathrm{O}$ \\
\hline & & & & & 300.2 & 1 & $\mathrm{M}-\mathrm{H}_{2} \mathrm{O}$ \\
\hline & 318.2 & 1 & 318.2 & $\mathbf{L W}$ & 205.1 & 1 & $\mathrm{y}_{1}$ \\
\hline & & & & & 188.1 & 1 & $\mathrm{z}_{1}$ \\
\hline & & & & & & 2 & a5 \\
\hline & & & & & & 3 & a6 \\
\hline & 335.2 & 3 & 335.2 & LKKYKVPQ & & 1 & $\mathrm{x} 1$ \\
\hline 8 & & & & & & 1 & y3 \\
\hline & & & & & - & 1 & $\mathrm{M}-\mathrm{NH}_{3}$ \\
\hline & 342.2 & 1 & 342.2 & IPI & & 1 & $\mathrm{M}-\mathrm{H}_{2} \mathrm{O}$ \\
\hline & & & 8675 & & 849.6 & 1 & $\mathrm{M}-\mathrm{H}_{2} \mathrm{O}$ \\
\hline & $86 \% .5$ & 1 & $86 \% .5$ & SKVLPVPQ & 641.4 & 1 & $\mathrm{c}_{6}$ \\
\hline & & & & & 287.1 & 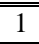 & 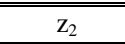 \\
\hline 9 & 361.2 & 1 & 361.2 & GVW & 129.1 & 1 & $\mathrm{a}_{2}$ \\
\hline 10 & - & - & - & 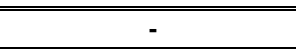 & - & - & - \\
\hline
\end{tabular}



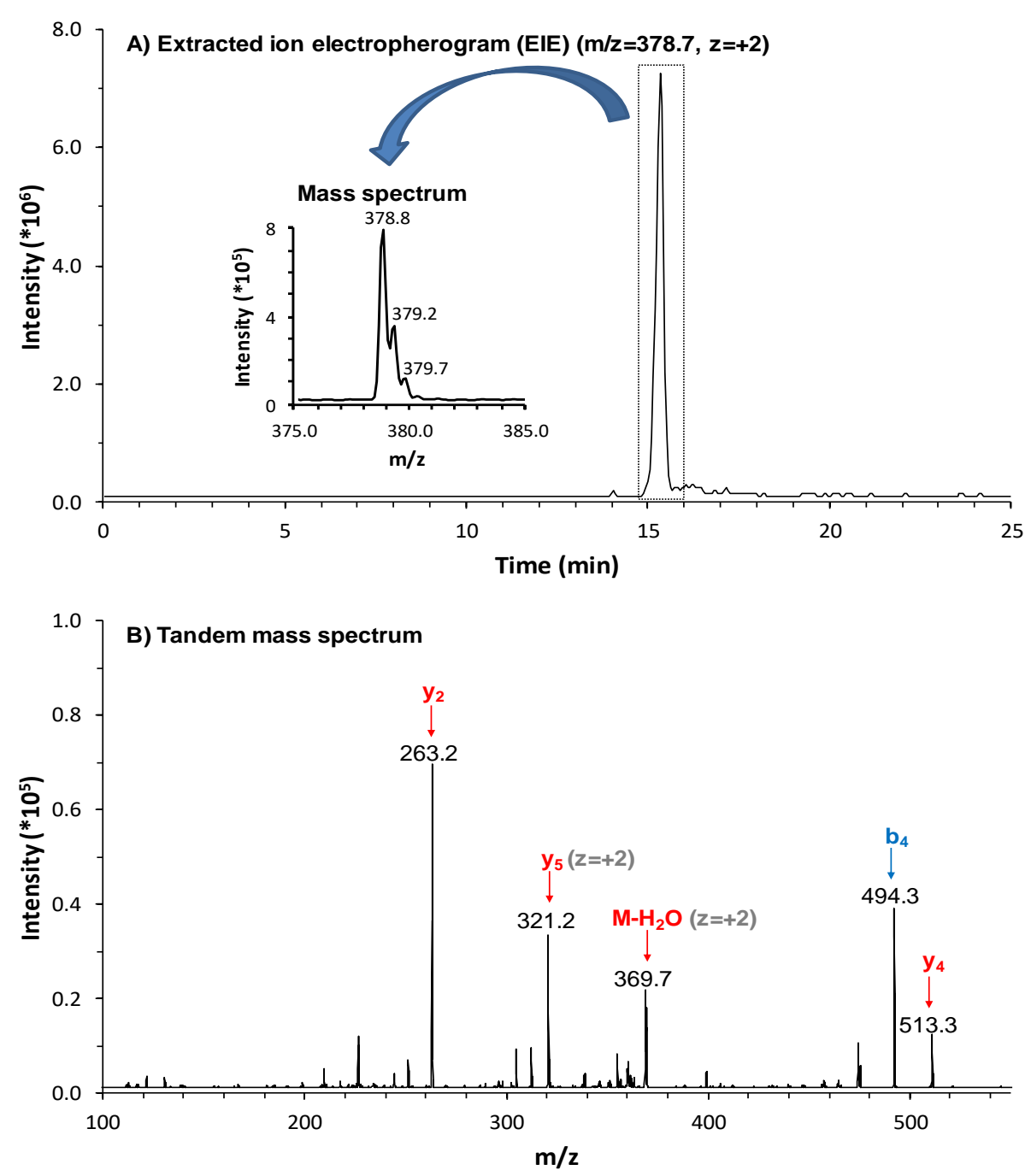

C) Peptide fragmentation

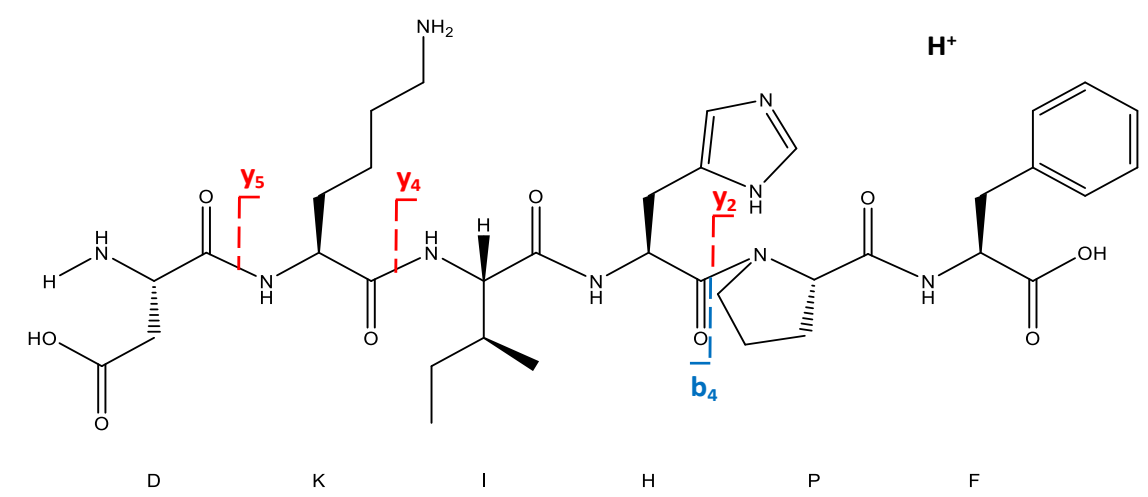

Figure S-1. (A) Experimental extracted ion electropherogram (EIE) and mass spectrum, (B) tandem mass spectrum and (C) peptide fragmentation obtained by CE-MS/MS for the antihypertensive peptide DKIHPF $\left(m / z_{\text {theoretical }}=378.7, \mathrm{z}=+2\right)$. 